\title{
Energy intake and food sources of eight Latin American countries: results from the Latin American Study of Nutrition and Health (ELANS)
}

Irina Kovalskys ${ }^{1,2, *}$, Mauro Fisberg ${ }^{3,4}$, Georgina Gómez ${ }^{5}$, Rossina G Pareja ${ }^{6}$, Martha C Yépez García ${ }^{7}$, Lilia Y Cortés Sanabria ${ }^{8}$, Marianella Herrera-Cuenca ${ }^{9}$, Attilio Rigotti $^{10}$, Viviana Guajardo', loná Zalcman Zimberg ${ }^{11}$, Agatha Nogueira Previdelli ${ }^{12}$, Luis A Moreno ${ }^{13,14}$, Berthold Koletzko ${ }^{15}$ and the ELANS Study Group $\dagger$

${ }^{1}$ Committee of Nutrition and Wellbeing, International Life Sciences Institute (ILSI Argentina), Av. Santa Fe 1145 , C1059ABF Buenos Aires, Argentina: 2Facultad de Ciencias Médicas, Pontifica Universidad Católica (UCA), Av. Alicia Moreau de Justo 1300, C 1107 AAZ Buenos Aires, Argentina: ${ }^{3}$ Instituto Pensi, Fundação Jose Luiz Egydio Setubal, Hospital Infantil Sabara, São Paulo, SP, Brazil: ${ }^{4}$ Departamento de Pediatria, Universidade Federal de São Paulo, São Paulo, SP, Brazil: ${ }^{5}$ Departamento de Bioquímica, Escuela de Medicina, Universidad de Costa Rica, San José, Costa Rica: ${ }^{6}$ Instituto de Investigación Nutricional, Lima, Peru: ${ }^{7}$ Colegio de Ciencias de la Salud, Universidad San Francisco de Quito, Quito, Ecuador: ${ }^{8}$ Departamento de Nutrición y Bioquímica, Pontificia Universidad Javeriana, Bogotá, Colombia: ${ }^{9}$ Centro de Estudiosdel Desarrollo, Universidad Central de Venezuela (CENDES-UCV)/Fundación Bengoa, Caracas, Venezuela: ${ }^{10}$ Departamento de Nutrición, Diabetes y Metabolismo, Centro de Nutrición Molecular y Enfermedades Crónicas, Escuela de Medicina, Pontificia Universidad Católica, Santiago, Chile: ${ }^{11}$ Departamento de Psicobiologia, Universidade Federal de São Paulo, São Paulo, SP, Brazil:

${ }^{12}$ Faculdade de Ciências Biológicas e da Saúde, Universidade São Judas Tadeu, São Paulo, SP, Brazil: ${ }^{13}$ Instituto de Investigación Sanitaria Aragón (IIS Aragón), Centro de Investigación Biomédica en Red Fisiopatología de la Obesidad y Nutrición (CIBERObn), University of Zaragoza, Zaragoza, Spain: ${ }^{14}$ GENUD (Growth, Exercise, Nutrition and Development) Research Group, Instituto Agroalimentario de Aragón (IA2), University of Zaragoza, Zaragoza, Spain: ${ }^{15}$ Ludwig-Maximilians-Universität Munich, Division of Metabolic and Nutritional Medicine, Dr. von Hauner Children's Hospital, University of Munich Medical Center, Munich, Germany

Submitted 23 December 2017: Final revision received 25 March 2018: Accepted 3 April 2018: First published online 31 May 2018

\begin{abstract}
Objective: Few previous studies in Latin America (LA) have provided data on dietary intake composition with a standardized methodology. The present study aimed to characterize energy intake (EI) and to describe the main food sources of energy in representative samples of the urban population from eight LA countries from the Latin American Study in Nutrition and Health (ELANS).

Design: Cross-sectional study. Usual dietary intake was assessed with two nonconsecutive $24 \mathrm{~h}$ dietary recalls.

Setting: Urban areas from eight countries (Argentina, Brazil, Chile, Colombia, Costa Rica, Ecuador, Peru, Venezuela), September 2014 to July 2015.

Subjects: Adolescents and adults aged 15-65 years. Final sample comprised 9218 individuals, of whom $6648(72 \cdot 1 \%)$ were considered plausible reporters.

Results: Overall, mean EI was $8196 \mathrm{~kJ} / \mathrm{d}(1959 \mathrm{kcal} / \mathrm{d})$, with a balanced distribution of macronutrients ( $54 \%$ carbohydrate, $30 \%$ fat, $16 \%$ protein). Main food sources of energy were grains, pasta and bread (28\%), followed by meat and eggs (19\%), oils and fats (10\%), non-alcoholic homemade beverages (6\%) and ready-to-drink beverages (6\%). More than $25 \%$ of EI was provided from food sources rich in sugar and fat, like sugary drinks, pastries, chips and candies. Meanwhile, only 18\% of EI was from food sources rich in fibre and micronutrients, such as whole grains, roots, fruits, vegetables, beans, fish and nuts. No critical differences were observed by gender or age.

Conclusions: Public health efforts oriented to diminish consumption of refined carbohydrates, meats, oils and sugar and to increase nutrient dense-foods are a priority in the region to drive to a healthier diet.
\end{abstract}

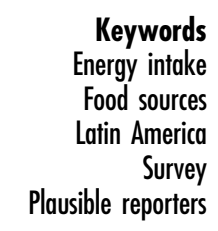

Keywords

Fon

Food sources

Survey

Plausible reporters

\footnotetext{
$\dagger$ A full list of the ELANS Study Group members is available in the Appendix.
} 
Most surveys on dietary sources of energy, diet composition and food patterns have been performed in North American or European countries. Relatively little information is available on dietary intakes within the Latin American region, which is still distinctive in its culture, agriculture, and food sources and habits. Differences in geographical location, climate, food access and level of economic development are key determinants of the Latin American diet ${ }^{(1,2)}$.

Latin American countries have been experiencing a nutrition transition during the last 40 years, moving from under- to overweight while still experiencing nutritional deficiencies $^{(1,3)}$. As a result of this transition, alarming rates of overweight (32.0\%) and obesity (19.6\%) have been described in most of the countries of the region, and these rates are projected to increase to 38.1 and $43.6 \%$, respectively, by $2030^{(4)}$. Total energy intake (EI) has increased substantially in most Western countries and this increase in energy supply has been directly associated with the increase in overweight and obesity prevalence ${ }^{(5)}$. In the USA, however, average EI did not change significantly between 1988 and $2010^{(6)}$.

It has been suggested that the excessive intake of energy is especially associated with the increased reliance on processed foods and high intakes of refined carbohydrates, added sugars, fats and animal-source foods ${ }^{(7)}$. Results from the National Health and Nutrition Examination Survey (NHANES) have shown that the percentage of energy from carbohydrate increased, whereas the percentage of energy from fat and protein decreased in the USA from 1971 to $2006^{(8,9)}$.

Few previous studies have provided detailed data on Latin American dietary composition with standardized accurate methodology and examined differences across countries and among regions within the same country. Identification of food sources of EI in representative samples of the Latin American population is necessary to determine feasible and appropriate dietary recommendations. Moreover, identification of the main food sources of energy is particularly important for supporting public health efforts to oppose the epidemic of obesity and other non-communicable diseases.

The purpose of the current study was to provide updated data on EI and its food sources in representative samples of the urban population from eight Latin American countries, assessed with the same methodology, to provide better understanding of the dietary practices of these populations with a focus on the differences between regions, age groups and gender.

\section{Methods}

The Latin American Study of Nutrition and Health (Estudio Latinoamericano de Nutrición y Salud; ELANS) is a household-based multinational cross-sectional survey.
ELANS aimed to describe the nutritional status in Latin America and to investigate food and nutrient intakes in representative samples from urban populations, where $80-90 \%$ of the population is living. Eight Latin American countries (i.e. Argentina, Brazil, Chile, Colombia, Costa Rica, Ecuador, Peru and Venezuela) were involved. The fieldwork for ELANS was conducted from September 2014 to July 2015.

\section{Sample}

The sample consisted of 9218 adolescents and adults aged 15-65 years from the urban population of eight Latin American countries. It was a random complex multistage sample, stratified by geographical region, gender, age and socio-economic level, with a random selection of primary sampling units and secondary sampling units. For the selection of households within each secondary sampling unit, households were selected through systematic randomization. Selection of a respondent within a household was done using $50 \%$ of the sample next birthday, $50 \%$ last birthday, controlling quotas for gender, age and socioeconomic level. The representative sample size was established with a confidence level of $95 \%$ and a maximum error of $3.49 \%$. Sample weighting was applied at each country level.

Socio-economic level was evaluated by questionnaire using a country-dependent format and based on the legislative requirements or established local standard layouts. The standard study protocol was designed to evaluate the nutritional intakes, physical activity levels and anthropometric measurements. More details of this study can be found in a previous publication ${ }^{(10)}$.

\section{Dietary assessment}

The dietary assessment was conducted face-to-face during two household visits on non-consecutive days, with an interval of up to $8 \mathrm{~d}$ between them. In both visits, a $24 \mathrm{~h}$ dietary recall was conducted by trained interviewers using the multiple-pass method ${ }^{(11)}$ to assess all foods and beverages consumed over the prior day. A photographic album containing the most commonly used household utensils and portion sizes was used to improve accuracy in the estimation of food servings. These were specific to each country, including local food item pictures and common utensils, and standardized within the country. The $24 \mathrm{~h}$ recalls included both weekdays and weekend days, with a proportional distribution of days among the sample, to capture the day-to-day variation in intakes. The $24 \mathrm{~h}$ recalls were supervised by trained nutritionists who were also responsible for converting the measures obtained into grams and millilitres. Data consistency was made at each site and a randomized double check was made by telephone.

The food and beverage intakes recorded were converted into energy, macronutrient and micronutrient 
values using the Nutrition Data System for Research (NDS-R version 2013; University of Minnesota, Minneapolis, MN, USA). To use the NDS-R software which is based on the US Department of Agriculture composition table, a standardized procedure matching local foods to US Department of Agriculture foods was conducted by professional nutritionists in each country to minimize errors and verify quantities of key nutrients, which, for the purpose of the present article, are referred to as energy and its sources from consumed foods. The complete procedure for standardization of the food composition database has been described in detail elsewhere ${ }^{(12)}$.

Regional foods without an exact equivalent available in the NDS-R database were broken down into ingredients and entered into the software as user recipes. Local teams were responsible for creating a recipe that represented the same nutritional value as the original version. They were obtained from national publications, recipe books and local culinary websites of each country and checked against actual data from $24 \mathrm{~h}$ recalls. Consistency checks were run to minimize errors and to verify results for key nutrients.

Food consumption was organized to characterize EI. A total of 3351 types of foods and beverages were reported in both $24 \mathrm{~h}$ recalls for all countries. They were grouped into ninety-three food items, according to nutritional similarities. In addition to the coding into ninetythree items, foods were further categorized into eighteen food groups, representing a larger and general group list. The list of the ninety-three food items and eighteen food groups is shown in Table 3. This categorization was based not only the nutritional value of each food, but also the food's preparation and eating time. The percentage contribution of each food item to EI was calculated using the weighted-proportions formula developed by Block et $a l^{(13)}$, in which the relative contribution (RC) of a given food item is defined as:

$$
\mathrm{RC}=\frac{\text { Total EI from a food item }}{\text { Total energy in all foods consumed }} .
$$

The percentage contribution of each food item to EI was calculated for the overall population, as well as separately for each country.

\section{Usual intake}

Two $24 \mathrm{~h}$ recalls were used to estimate usual food consumption and to evaluate intra-individual variability in nutrient intakes. The web-based statistical modelling technique Multiple Source Method (MSM; https://msm. dife.de/tps/en), proposed by the European Prospective Investigation into Cancer and Nutrition (EPIC), was used to estimate energy and macronutrient intakes. This method was chosen because of its capability to improve estimates of usual dietary intake of energy, nutrients, foods and food groups by considering within-person variance in the intake, thereby improving the usual intake distribution for the population ${ }^{(14)}$. It has also been largely used in other Latin American studies for usual intake estimation ${ }^{(15-17)}$. To minimize errors derived from the method, the estimation of usual intakes was conducted individually for each country, thus taking differences in eating habits among the Latin American populations into account. The relative contribution of each macronutrient to total EI was subsequently calculated.

\section{Antbropometry}

The anthropometric measurements of body weight, height and waist, hip and neck circumferences were collected according to standardized procedures ${ }^{(10)}$. Categorization of nutritional status by BMI in adolescents (15-19 years old) was based on the gender-specific BMI-for-age cut-off points from the $\mathrm{WHO}^{(18)}$ for underweight (BMI-for-age $<-2 \mathrm{SD}$ ), normal weight $(-2 \mathrm{SD} \geq$ BMI-for-age $\leq 1 \mathrm{SD})$, overweight $(1 \mathrm{SD} \geq$ BMI-for-age $\leq 2 \mathrm{SD}$ ) and obesity (BMI-for-age $>2 \mathrm{SD}$ ) categories. For adults and elderly (older than 19 years), BMI was categorized as underweight $\left(<18.5 \mathrm{~kg} / \mathrm{m}^{2}\right)$, normal weight $\left(18.5-24.9 \mathrm{~kg} / \mathrm{m}^{2}\right)$, overweight $\left(25.0-29.9 \mathrm{~kg} / \mathrm{m}^{2}\right)$ and obesity $\left(\geq 30 \cdot 0 \mathrm{~kg} / \mathrm{m}^{2}\right)^{(19)}$.

\section{Physical activity}

Physical activity was assessed by the International Physical Activity Questionnaire (IPAQ) - Long Form, adapted from the Mexican (Spanish) version, allowing the determination of levels of physical activity as well as sedentary habit. More details are available in a previous publication ${ }^{(10)}$. In the present study, the information collected by the IPAQ was used to predict the total energy expenditure (TEE) on physical activities for each participant. The TEE was estimated from the participant's age, height, weight and overall activity level using a predictive equation developed by the Institute of Medicine ${ }^{(20)}$. Briefly, the level of each individual activity for each participant was calculated as a function of the participant's basal energy expenditure and body weight and the duration and metabolic equivalent of task score of each activity. The physical activity level $(\triangle \mathrm{PAL})$ for each participant was determined by summing up the PAL across all individual activities that were done by that participant. Finally, the TEE was predicted based on the Dietary Reference Intake equations and then used to identify the misreporters of EI, as described below.

\section{Misreporting of energy intake}

Misreporting of EI was calculated based on the methodology used by McCrory et $a l .{ }^{(21)}$, according to the following equation:

$$
\mathrm{SD}=\sqrt{\left(\mathrm{CV}_{\mathrm{wEI}}^{2} / d\right)+\mathrm{CV}_{\mathrm{wpTEE}}^{2}+\mathrm{CV}_{\mathrm{pTEE}}^{2}}
$$

where $\mathrm{CV}_{\mathrm{wEI}}$ is the within-subject $\mathrm{CV}$ in EI over the number of days of diet assessment $(d), \mathrm{CV}_{\text {wpteE }}$ is the 
within-subject $\mathrm{CV}$ of measuring the TEE by the doubly labelled water method and $\mathrm{CV}_{\text {pTEE }}$ is the $\mathrm{CV}$ of predicting the TEE. In the present study, $\mathrm{CV}_{\mathrm{wEI}}(31.2 \%)$ was estimated based on both $24 \mathrm{~h}$ recalls from the overall ELANS population, so the number of days (d) was two. $\mathrm{CV}_{\text {wpTEE }}$ was set to $8 \cdot 2 \%$, as estimated from doubly labelled water measurements ${ }^{(22)}$ and $\mathrm{CV}_{\text {pTEE }}$ was $17.7 \%$, as estimated from prediction equations of $\mathrm{TEE}^{(21,23)}$. To identify the misreporting, the $\pm 1.5 \mathrm{SD}$ cut-off point was used to statistically compare reported EI with predicted TEE (EI:TEE). Under-reporting was defined as EI:TEE $<-1.5 \mathrm{SD}$ and over-reporting as EI:TEE $>+1.5 \mathrm{SD}$. It should be highlighted that EI from the first $24 \mathrm{~h}$ recall was used in this approach ${ }^{(24,25)}$.

\section{Ethics}

The ELANS protocol was approved by the Western Institutional Review Board (\#20140605) and registered at clinicaltrials.gov (\#NCT02226627). It was also approved by a local ethics committee in each country. All participants gave their informed consent/assent before participation in the survey. The complete design, protocol and methodology of ELANS have been described elsewhere ${ }^{(10)}$.

\section{Statistical analysis}

Descriptive analyses of central tendency and dispersion were applied to estimate and describe the population according to gender, age group (adolescents (15-19 years old), younger adults (20-34 years), adults (35-49 years) and older adults (50-65 years)), socio-economic level (low, medium and high) and nutritional status (underweight, normal weight, overweight and obesity) by each country. Linear regression analysis was performed to identify the independent predictors of EI, considering a $P$ value of $<0.05$ as statistically significant. All analyses were carried out using the statistical software package Intercooled Stata version 13.0.

\section{Results}

Of 10134 eligible participants initially assessed in the first visit, 9680 participants had two complete visits and 9218 participants satisfied the analysis of inconsistencies or partially missing data (Fig. 1). Overall and country-level population sociodemographic characteristics are shown in Table 1 . The largest sample was from Brazil ( $n$ 2000) and the smallest from Costa Rica ( $n$ 798). Overall, $52 \cdot 2 \%$ were women, $37 \cdot 7 \%$ were aged $20-34$ years and $38.4 \%$ were categorized as medium socio-economic level. Most of the sample had excess weight (59.6\%), with the highest proportion in Chile $(68.6 \%)$ and the lowest proportion in Colombia (50.7\%). After adjusting for misreporting, the plausible reporters were 6648 individuals (72.1\%), who were used for further analyses.

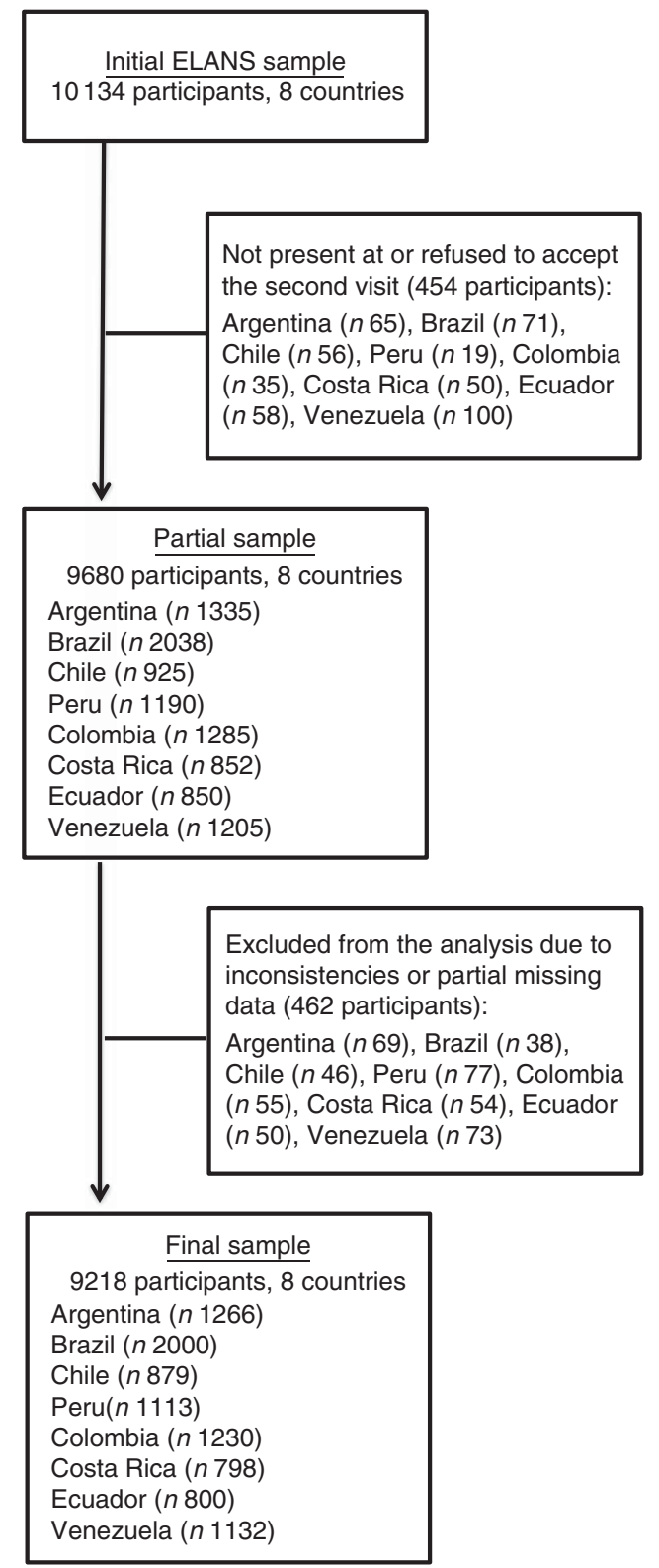

Fig. 1 Flow diagram of the study participants in the Latin American Study of Nutrition and Health (ELANS)

\section{Energy intake and distribution}

Usual EI and macronutrients as a percentage of EI by country, gender and age of the plausible reporters are shown in Table 2. Mean EI was 8196 (SD 1954) kJ/d (1959 (SD 467.1) $\mathrm{kcal} / \mathrm{d})$. Ecuador had the highest reported EI $(8828 \mathrm{~kJ} / \mathrm{d}$ $(2110 \mathrm{kcal} / \mathrm{d}))$ and Chile the lowest $(7448 \mathrm{~kJ} / \mathrm{d}(1780 \mathrm{kcal} / \mathrm{d}))$. Men reported higher EI than women $(P<0 \cdot 001)$, independent of age group and country. Adolescents reported consuming more energy than middle-aged and older groups $(P<$ 0.001). In all countries, the highest EI was observed in young men and the lowest in older women, with a difference of approximately $2510 \mathrm{~kJ} / \mathrm{d}(600 \mathrm{kcal} / \mathrm{d})$. The mean contribution of macronutrients to EI was 54.4 (SD 6.9) \% for carbohydrate, 29.6 (SD 5.7) \% for fat and 16.0 (SD 2.9) \% for protein. Peru had the highest percentage of energy derived 
Table 1 Sociodemographic characteristics of adolescents and adults aged 15-65 years in the Latin American Study of Nutrition and Health (ELANS), September 2014-July 2015*

\begin{tabular}{|c|c|c|c|c|c|c|c|c|c|c|c|c|c|c|c|c|c|c|}
\hline & \multicolumn{2}{|c|}{ ELANS } & \multicolumn{2}{|c|}{ Argentina } & \multicolumn{2}{|c|}{ Brazil } & \multicolumn{2}{|c|}{ Chile } & \multicolumn{2}{|c|}{ Colombia } & \multicolumn{2}{|c|}{$\begin{array}{c}\text { Costa } \\
\text { Rica }\end{array}$} & \multicolumn{2}{|c|}{ Ecuador } & \multicolumn{2}{|c|}{ Peru } & \multicolumn{2}{|c|}{ Venezuela } \\
\hline & $n$ & $\%$ & $n$ & $\%$ & $n$ & $\%$ & $n$ & $\%$ & $n$ & $\%$ & $n$ & $\%$ & $n$ & $\%$ & $n$ & $\%$ & $n$ & $\%$ \\
\hline $\begin{array}{l}\text { Samp } \\
\text { Gend }\end{array}$ & 218 & $100 \cdot 0$ & 1266 & $100 \cdot 0$ & 2000 & $100 \cdot 0$ & 879 & $100 \cdot 0$ & 1230 & $100 \cdot 0$ & 798 & $100 \cdot 0$ & 800 & $100 \cdot 0$ & 1113 & $100 \cdot 0$ & 1132 & $100 \cdot 0$ \\
\hline Men & 09 & $47 \cdot 8$ & 573 & $45 \cdot 3$ & 942 & $47 \cdot 1$ & 425 & $48 \cdot 4$ & 603 & $49 \cdot 0$ & 394 & $49 \cdot 4$ & 397 & $49 \cdot 6$ & 523 & $47 \cdot 0$ & 552 & $48 \cdot 8$ \\
\hline Women & 4809 & $52 \cdot 2$ & 693 & $54 \cdot 7$ & 1058 & 52.9 & 454 & 51.6 & 627 & $51 \cdot 0$ & 404 & $50 \cdot 6$ & 403 & $50 \cdot 4$ & 590 & 53.0 & 580 & $51 \cdot 2$ \\
\hline \multicolumn{19}{|l|}{ Age (years) } \\
\hline $15-19$ years & 223 & $13 \cdot 3$ & 152 & $12 \cdot 1$ & 235 & $11 \cdot 8$ & 118 & 13.4 & 148 & $12 \cdot 0$ & 121 & $15 \cdot 2$ & 128 & $16 \cdot 0$ & 165 & $14 \cdot 8$ & 156 & $13 \cdot 8$ \\
\hline & 179 & $37 \cdot 7$ & 446 & $35 \cdot 2$ & 745 & $37 \cdot 2$ & 307 & 34.9 & 445 & $36 \cdot 2$ & 301 & $37 \cdot 7$ & 316 & 39.5 & 460 & 41.3 & 59 & 40.5 \\
\hline & 27 & 28.5 & 379 & 29.9 & 608 & $30 \cdot 4$ & 252 & 28.7 & 335 & $27 \cdot 2$ & 224 & $28 \cdot 1$ & 222 & $27 \cdot 8$ & 294 & $26 \cdot 4$ & 313 & $27 \cdot 7$ \\
\hline 50-65 years & 1889 & 20.5 & 289 & $22 \cdot 8$ & 412 & $20 \cdot 6$ & 202 & 23.0 & 302 & $24 \cdot 6$ & 152 & $19 \cdot 0$ & 134 & $16 \cdot 8$ & 194 & $17 \cdot 4$ & 204 & $18 \cdot 0$ \\
\hline \multicolumn{19}{|l|}{ Socio-economic le } \\
\hline High & 880 & 9.6 & 65 & $5 \cdot 1$ & 169 & 8.4 & 80 & $9 \cdot 1$ & 67 & 5.4 & 108 & $13 \cdot 5$ & 104 & $13 \cdot 0$ & 225 & $20 \cdot 2$ & 62 & 5.5 \\
\hline Mediu & 542 & 38.4 & 585 & $46 \cdot 2$ & 915 & $45 \cdot 8$ & 388 & 44.1 & 384 & $31 \cdot 2$ & 428 & 53.6 & 297 & $37 \cdot 1$ & 355 & 31.9 & 190 & $16 \cdot 8$ \\
\hline Low & 96 & $52 \cdot 0$ & 616 & $48 \cdot 7$ & 916 & $45 \cdot 8$ & 411 & 46.8 & 779 & $63 \cdot 3$ & 262 & $32 \cdot 8$ & 339 & $49 \cdot 9$ & 533 & 47.9 & 880 & $77 \cdot 7$ \\
\hline \multicolumn{19}{|l|}{ BMI } \\
\hline Underweight & 306 & $3 \cdot 3$ & 37 & $2 \cdot 9$ & 87 & 4.3 & 5 & 0.6 & 59 & 4.8 & 27 & 3.4 & 28 & 3.5 & 24 & $2 \cdot 2$ & 39 & 3.5 \\
\hline Norm & 3420 & $37 \cdot 1$ & 493 & 38.9 & 749 & 37.5 & 271 & $30 \cdot 8$ & 548 & 44.5 & 267 & $33 \cdot 4$ & 288 & $36 \cdot 0$ & 414 & 37.5 & 390 & 34.5 \\
\hline Over & 167 & 34.4 & 399 & 31.5 & 664 & 33.2 & 332 & 37.8 & 419 & $34 \cdot 1$ & 260 & $32 \cdot 6$ & 287 & 35.9 & 422 & $38 \cdot 3$ & 384 & 33.9 \\
\hline Obesity & 2315 & $25 \cdot 2$ & 337 & $26 \cdot 6$ & 500 & 25.0 & 271 & 30.8 & 204 & $16 \cdot 6$ & 244 & $30 \cdot 6$ & 197 & $24 \cdot 6$ & 243 & $22 \cdot 0$ & 319 & $28 \cdot 1$ \\
\hline
\end{tabular}

*Including the whole sample of the ELANS (plausible and non-plausible cases).

from carbohydrate (62.9\%) and Argentina and Brazil the lowest (51.3 and $51.5 \%$, respectively). Argentina had the highest percentage of energy derived from fat $(32.6 \%)$ and Brazil the highest from protein (17.8\%), while Peru had the lowest proportion of energy provided by both macronutrients (22.3\% for fat and $14.8 \%$ for protein). Costa Rica also had a low percentage of energy from protein (14.5\%). Percentage of energy provided by different macronutrients was similar across age groups and gender.

\section{Energy intake contribution from foods and beverages}

Main food and beverage sources of energy at country level, ranked as a percentage of EI from high to low, are shown in Table 3. The grains, pasta and bread group was the main source of energy in all countries $(27 \cdot 8 \%$ of EI), with the highest proportions observed in Peru and Chile (35.9 and $32.9 \%$ of EI, respectively). Within the grains, pasta and bread group, rice was the major source of EI in Peru, Colombia, Costa Rica and Ecuador, while bread was the major source in Argentina, Brazil and Chile. Refinedgrain products were the major sources only in Venezuela, especially due to corn flour used for homemade arepas.

Meat and eggs were the second main source of energy in all countries (18.9\% of EI). Within this group, nonprocessed beef and poultry represented the major sources for all countries ( $9.7 \%$ of EI). Overall, fish was almost nonexistent in terms of contribution to energy ( $0.9 \%$ of EI). Exceptions were Peru and Ecuador, where the intake of processed meats was half that in the rest of the countries and had little influence on EI.

Oils and fats were the third major energy source in all countries $(9.7 \%$ of EI). Within this group, vegetable oil represented the major source ( $6 \cdot 1 \%$ of EI), followed by butter and margarine (only $1.6 \%$ of EI). Interestingly, the intake of margarine was higher than that of butter in Brazil, Peru, Colombia, Costa Rica and Venezuela, while the opposite occurred in Argentina, Chile and Ecuador.

Non-alcoholic beverages were the fourth major source of energy in all countries (12.1\% of EI), with an extremely high contribution to total energy in Venezuela (14.6\% of EI). Soft drinks were the main source of total energy from beverages in all countries ( $3.9 \%$ of EI), followed by natural fruit juices with added sugar (2.9\% of EI), except for Argentina and Chile where soft drinks were followed by ready-to-drink juices with sugar $(2.3$ and $2.2 \%$ of EI, respectively). In Brazil, there were similar proportions of EI from natural fruit juices with added sugar and ready-todrink juices with sugar (1.9 and $1.5 \%$ of EI, respectively). Interestingly, Venezuela and Argentina were the countries with highest intake of energy from non-alcoholic beverages (above $14 \%$ of EI), while the rest of the countries consumed between 10 and $12 \%$ of EI, but not from equal sources.

Dietary sources of EI from foods and beverages were similar between genders (see online supplementary material, Supplemental Table 1), except for the alcoholic beverages group in which men had a higher energy percentage than women ( $4 \cdot 1 v \cdot 1 \cdot 6 \%$ of EI, respectively), and the sugars and sweets group in which women had a higher energy percentage than men ( $4 \cdot 2 v \cdot 2 \cdot 9 \%$ of EI, respectively).

\section{Discussion}

In this first characterization of the dietary intake of representative samples of the urban population of eight 
Table 2 Energy and macronutrient intakes, by age group, gender and country, among adolescents and adults aged 15-65 years in the Latin American Study of Nutrition and Health (ELANS), September 2014-July 2015*

\begin{tabular}{|c|c|c|c|c|c|c|c|c|c|c|c|c|c|c|c|c|}
\hline & \multicolumn{4}{|c|}{ Overall } & \multicolumn{3}{|c|}{$15-19$ years } & \multicolumn{3}{|c|}{ 20-34 years } & \multicolumn{3}{|c|}{$35-49$ years } & \multicolumn{3}{|c|}{ 50-65 years } \\
\hline & $n$ & Total & Men & Women & Total & Men & Women & Total & Men & Women & Total & Men & Women & Total & Men & Women \\
\hline \multicolumn{17}{|c|}{ Energy intake $(\mathrm{kcal} / \mathrm{d}) \dagger$} \\
\hline Argentina & 879 & $2103 \cdot 17$ & 2383.26 & $1862 \cdot 76$ & 2232.79 & 2489.22 & 1838.75 & $2151 \cdot 28$ & 2410.08 & 1916.00 & 2092.57 & 2379.21 & 1888.62 & 1987.32 & 2274.74 & 1770.57 \\
\hline Brazil & 1406 & 1865.53 & 2079.34 & 1677.45 & $1997 \cdot 12$ & $2201 \cdot 16$ & 1697.44 & 1953.72 & 2164.04 & 1757.47 & 1846.39 & 2038.76 & $1686 \cdot 35$ & 1665.87 & 1864.76 & 1536.65 \\
\hline Chile & 625 & $1780 \cdot 82$ & 2005.08 & 1565.69 & $1860 \cdot 42$ & 2067.59 & 1627.35 & 1837.99 & 2101.67 & 1597.86 & 1768.89 & $2006 \cdot 86$ & $1544 \cdot 13$ & 1668.81 & 1831.90 & 1512.08 \\
\hline Peru & 876 & $2031 \cdot 15$ & 2253.86 & 1818.39 & $2043 \cdot 11$ & 2232.57 & 1783.06 & 2093.74 & $2329 \cdot 31$ & 1874.72 & 2039.90 & 2283.34 & 1828.29 & 1863.96 & $2050 \cdot 85$ & 1697.57 \\
\hline Colombia & 875 & 2035.83 & 2233.05 & 1846.98 & $2128 \cdot 73$ & $2313 \cdot 31$ & $1872 \cdot 36$ & $2123 \cdot 81$ & $2329 \cdot 24$ & $1906 \cdot 45$ & $2026 \cdot 86$ & $2208 \cdot 26$ & $1865 \cdot 62$ & 1878.76 & 2054.20 & 1742.46 \\
\hline Costa Rica & 551 & 1892.68 & $2141 \cdot 71$ & 1640.92 & 1947.93 & $2100 \cdot 30$ & 1752.59 & $2007 \cdot 17$ & 2258.75 & 1735.67 & 1853.30 & $2100 \cdot 86$ & 1588.32 & 1671.99 & 1961.21 & $1479 \cdot 17$ \\
\hline Ecuador & 574 & 2110.43 & 2313.41 & 1894.30 & 2152.20 & 2307.91 & 1955.52 & 2211.84 & $2380 \cdot 24$ & 2003.43 & 2067.86 & 2316.62 & 1809.78 & 1912.72 & 2104.54 & 1782.66 \\
\hline Venezuela & 862 & 1887.39 & 2060.24 & 1727.66 & 1946.76 & $2102 \cdot 30$ & $1780 \cdot 31$ & 1940.04 & 2102.73 & $1781 \cdot 10$ & 1866.34 & 2054.78 & 1685.68 & 1763.89 & 1923.58 & 1652.45 \\
\hline ELANS & 6648 & 1959.46 & 2178.87 & 1754.22 & 2035.83 & 2230.25 & $1780 \cdot 32$ & $2035 \cdot 21$ & 2253.68 & 1819.88 & 1943.66 & $2163 \cdot 70$ & $1749 \cdot 27$ & 1799.85 & $2005 \cdot 90$ & 1645.50 \\
\hline \multicolumn{17}{|c|}{ Carbohydrate (\% of energy intake) } \\
\hline Argentina & 879 & $51 \cdot 33$ & $51 \cdot 36$ & $51 \cdot 31$ & $51 \cdot 82$ & $52 \cdot 86$ & $50 \cdot 21$ & 51.48 & $51 \cdot 88$ & $51 \cdot 11$ & $51 \cdot 20$ & $50 \cdot 97$ & $51 \cdot 37$ & 51.07 & $50 \cdot 02$ & 51.87 \\
\hline Brazil & 1406 & 51.52 & 51.47 & 51.57 & 51.83 & 52.06 & 51.49 & 51.62 & $51 \cdot 16$ & 52.05 & 51.66 & $52 \cdot 12$ & $51 \cdot 28$ & 50.99 & 50.55 & 51.27 \\
\hline Chile & 625 & $54 \cdot 21$ & 54.57 & 53.87 & 54.98 & $54 \cdot 81$ & $55 \cdot 17$ & 54.49 & 54.48 & 54.50 & $53 \cdot 36$ & 54.39 & 52.39 & 54.37 & 54.75 & 54.00 \\
\hline Peru & 876 & 62.91 & 63.82 & 62.04 & 63.56 & 64.54 & $62 \cdot 21$ & $62 \cdot 61$ & 63.21 & 62.06 & 62.92 & 63.73 & $62 \cdot 21$ & 63.07 & 64.69 & 61.63 \\
\hline Colombia & 875 & 53.87 & 53.60 & 54.13 & 53.53 & 53.59 & 53.44 & 53.02 & 52.39 & 53.70 & $54 \cdot 33$ & $54 \cdot 22$ & 54.42 & $54 \cdot 71$ & 54.91 & 54.56 \\
\hline Costa Rica & 551 & 57.19 & 57.26 & $57 \cdot 11$ & 57.43 & 58.48 & 56.07 & $56 \cdot 25$ & 55.91 & $56 \cdot 61$ & 58.07 & 58.75 & $57 \cdot 34$ & 57.63 & 56.63 & 58.29 \\
\hline Ecuador & 574 & 54.02 & 54.07 & 53.96 & 54.69 & 53.71 & 55.94 & 53.61 & 54.03 & $53 \cdot 10$ & 53.69 & 53.91 & 53.47 & 54.89 & 54.98 & 54.84 \\
\hline Venezuela & 862 & 52.92 & $52 \cdot 64$ & $53 \cdot 18$ & 51.88 & $52 \cdot 36$ & $51 \cdot 36$ & 52.49 & 51.74 & $53 \cdot 22$ & $53 \cdot 23$ & 53.56 & 52.92 & $54 \cdot 13$ & 53.57 & 54.52 \\
\hline ELANS & 6648 & 54.43 & 54.57 & 54.29 & 54.88 & 55.27 & 54.36 & $54 \cdot 30$ & $54 \cdot 15$ & 54.45 & 54.38 & 54.83 & 53.98 & 54.43 & 54.47 & 54.40 \\
\hline \multicolumn{17}{|c|}{ Total fat (\% of energy intake) } \\
\hline Argentina & 879 & 32.59 & $32 \cdot 44$ & 32.72 & $32 \cdot 38$ & 31.48 & 33.75 & $32 \cdot 80$ & $32 \cdot 35$ & 33.20 & 32.56 & 32.58 & 32.55 & 32.44 & 33.05 & 31.98 \\
\hline Brazil & 1406 & 30.66 & 30.50 & $30 \cdot 81$ & 31.05 & 30.76 & 31.48 & $30 \cdot 76$ & 30.80 & $30 \cdot 73$ & 30.52 & 29.99 & $30 \cdot 96$ & 30.49 & 30.52 & 30.47 \\
\hline Chile & 625 & $30 \cdot 17$ & 30.03 & $30 \cdot 30$ & 30.41 & 30.96 & 29.79 & 29.97 & $30 \cdot 16$ & $29 \cdot 81$ & $30 \cdot 85$ & $30 \cdot 12$ & 31.53 & 29.51 & $29 \cdot 18$ & 29.84 \\
\hline Peru & 876 & $22 \cdot 32$ & 21.49 & $23 \cdot 12$ & 22.06 & 21.08 & 23.41 & $22 \cdot 61$ & 22.07 & $23 \cdot 11$ & $22 \cdot 25$ & 21.37 & 23.01 & 21.97 & $20 \cdot 67$ & $23 \cdot 13$ \\
\hline Colombia & 875 & $30 \cdot 82$ & 31.25 & $30 \cdot 42$ & 31.51 & 31.65 & 31.31 & 31.75 & 32.48 & 30.98 & 30.41 & 30.65 & $30 \cdot 20$ & 29.67 & 29.64 & 29.69 \\
\hline Costa Rica & 551 & $28 \cdot 36$ & $28 \cdot 17$ & 28.55 & $28 \cdot 74$ & 27.95 & 29.75 & $29 \cdot 15$ & $29 \cdot 10$ & $29 \cdot 20$ & 27.56 & 26.94 & $28 \cdot 21$ & 27.58 & $28 \cdot 24$ & $27 \cdot 14$ \\
\hline Ecuador & 574 & 30.11 & 30.08 & $30 \cdot 15$ & 29.93 & 30.69 & 28.98 & 30.48 & $30 \cdot 16$ & 30.87 & 30.41 & 30.18 & 30.64 & 28.96 & 28.91 & 29.00 \\
\hline Venezuela & 862 & $30 \cdot 63$ & 30.87 & $30 \cdot 40$ & 32.08 & 31.54 & 32.66 & 30.95 & 31.57 & $30 \cdot 34$ & $30 \cdot 31$ & 30.00 & $30 \cdot 61$ & $29 \cdot 34$ & 29.98 & 28.90 \\
\hline ELANS & 6648 & 29.55 & $29 \cdot 41$ & 29.68 & $29 \cdot 70$ & $29 \cdot 36$ & $30 \cdot 15$ & 29.75 & 29.82 & 29.69 & 29.51 & 29.09 & $29 \cdot 88$ & $29 \cdot 15$ & $29 \cdot 07$ & 29.21 \\
\hline \multicolumn{17}{|c|}{ Protein ( $\%$ of energy intake) } \\
\hline Argentina & 879 & $16 \cdot 08$ & $16 \cdot 20$ & $15 \cdot 97$ & $15 \cdot 81$ & $15 \cdot 66$ & $16 \cdot 03$ & $15 \cdot 73$ & $15 \cdot 77$ & $15 \cdot 69$ & $16 \cdot 24$ & $16 \cdot 45$ & 16.09 & $16 \cdot 48$ & 16.93 & $16 \cdot 15$ \\
\hline Brazil & 1406 & $17 \cdot 81$ & 18.03 & $17 \cdot 62$ & $17 \cdot 12$ & $17 \cdot 18$ & 17.03 & $17 \cdot 62$ & 18.05 & $17 \cdot 22$ & 17.82 & 17.89 & $17 \cdot 76$ & 18.52 & 18.93 & $18 \cdot 25$ \\
\hline Chile & 625 & $15 \cdot 62$ & $15 \cdot 41$ & $15 \cdot 83$ & 14.61 & $14 \cdot 23$ & 15.04 & 15.54 & $15 \cdot 37$ & $15 \cdot 70$ & 15.79 & 15.49 & 16.08 & $16 \cdot 11$ & 16.07 & $16 \cdot 16$ \\
\hline Peru & 876 & 14.77 & $14 \cdot 70$ & 14.84 & 14.38 & $14 \cdot 37$ & $14 \cdot 38$ & 14.78 & $14 \cdot 72$ & 14.83 & 14.84 & 14.90 & 14.78 & 14.96 & 14.65 & $15 \cdot 24$ \\
\hline Colombia & 875 & $15 \cdot 31$ & $15 \cdot 16$ & 15.45 & 14.96 & 14.76 & $15 \cdot 25$ & $15 \cdot 22$ & $15 \cdot 13$ & $15 \cdot 32$ & $15 \cdot 26$ & $15 \cdot 13$ & $15 \cdot 39$ & 15.62 & 15.45 & 15.75 \\
\hline Costa Rica & 551 & 14.45 & 14.57 & 14.34 & 13.84 & 13.57 & $14 \cdot 18$ & 14.61 & 14.99 & 14.19 & 14.38 & $14 \cdot 31$ & 14.45 & 14.79 & $15 \cdot 12$ & 14.56 \\
\hline Ecuador & 574 & $15 \cdot 87$ & 15.85 & 15.89 & 15.37 & 15.60 & 15.09 & 15.91 & 15.81 & 16.04 & 15.90 & 15.91 & 15.89 & $16 \cdot 14$ & $16 \cdot 11$ & $16 \cdot 16$ \\
\hline Venezuela & 862 & 16.45 & 16.49 & $16 \cdot 42$ & $16 \cdot 04$ & $16 \cdot 10$ & $15 \cdot 98$ & 16.56 & 16.69 & 16.43 & 16.45 & 16.44 & 16.47 & 16.53 & 16.45 & 16.58 \\
\hline ELANS & 6648 & $16 \cdot 02$ & $16 \cdot 02$ & $16 \cdot 02$ & $15 \cdot 42$ & $15 \cdot 38$ & 15.49 & 15.94 & 16.03 & $15 \cdot 86$ & $16 \cdot 11$ & $16 \cdot 07$ & $16 \cdot 13$ & $16 \cdot 42$ & $16 \cdot 46$ & 16.39 \\
\hline
\end{tabular}


Nutrition and Health (ELANS), September 2014-July 2015*

\begin{tabular}{|c|c|c|c|c|c|c|c|c|c|}
\hline Food group/subgroup & ELANS & Argentina & Brazil & Chile & Colombia & Costa Rica & Ecuador & Peru & Venezuela \\
\hline Grains, pasta and bread & $27 \cdot 84$ & 24.72 & $25 \cdot 64$ & $32 \cdot 85$ & 23.53 & $28 \cdot 36$ & $27 \cdot 61$ & 35.86 & 28.07 \\
\hline Refined-grain products & 14.29 & 19.72 & 13.51 & $25 \cdot 13$ & 11.71 & 10.29 & 8.89 & 9.09 & 17.35 \\
\hline Rice (white or brown) & 9.81 & 1.61 & 8.57 & 3.56 & 9.79 & $16 \cdot 18$ & $15 \cdot 52$ & 20.57 & 5.46 \\
\hline Pasta (white and whole flour) & 2.94 & 2.83 & 3.27 & 3.57 & 1.30 & 1.41 & 2.04 & $4 \cdot 13$ & 4.50 \\
\hline Wholegrain products & 0.81 & 0.56 & 0.29 & 0.60 & 0.73 & 0.49 & 1.15 & 2.07 & 0.77 \\
\hline Meat (not processed) and eggs & $14 \cdot 24$ & $13 \cdot 87$ & 15.99 & $10 \cdot 72$ & 14.98 & 11.67 & $16 \cdot 21$ & $14 \cdot 17$ & 13.56 \\
\hline Beef (not processed) & $5 \cdot 12$ & $6 \cdot 40$ & 7.77 & 3.03 & 5.57 & 2.34 & $5 \cdot 60$ & 2.07 & 4.86 \\
\hline Poultry (not processed) & 4.59 & 3.97 & $4 \cdot 34$ & 3.02 & 4.05 & 3.66 & $5 \cdot 36$ & $6 \cdot 84$ & $5 \cdot 04$ \\
\hline Eggs & 1.94 & 2.35 & 1.25 & 2.04 & 2.94 & 1.94 & 1.45 & 2.07 & 1.61 \\
\hline Pork (not processed) & 1.20 & 0.54 & 1.15 & 0.99 & 1.46 & $2 \cdot 70$ & 1.70 & 0.76 & 1.03 \\
\hline Fish (not processed) & 0.89 & 0.33 & 0.99 & 0.60 & 0.63 & 0.74 & 1.55 & 1.57 & 0.72 \\
\hline Liver and organ meats & 0.26 & 0.25 & 0.37 & 0.05 & 0.28 & 0.14 & 0.31 & 0.29 & 0.21 \\
\hline Lamb, veal, game & 0.17 & 0.03 & 0.02 & 0.95 & 0.01 & 0.02 & 0.07 & 0.48 & 0.07 \\
\hline Seafood & 0.07 & 0.01 & 0.10 & 0.05 & 0.03 & 0.12 & 0.17 & 0.09 & 0.03 \\
\hline Oils, fats and dressings & 9.74 & 9.41 & 10.66 & $9 \cdot 23$ & 10.09 & 9.43 & 11.22 & 7.64 & 9.86 \\
\hline Oils (vegetable) & $6 \cdot 10$ & 5.92 & $5 \cdot 74$ & 4.47 & $5 \cdot 32$ & $6 \cdot 62$ & 8.81 & $6 \cdot 20$ & 6.34 \\
\hline Margarine or shortening, vegetable oil & 1.60 & 0.24 & 3.28 & 0.86 & 1.95 & 1.32 & 0.65 & 0.52 & 2.73 \\
\hline Butter & 1.04 & 1.71 & 1.19 & 2.53 & 1.16 & 0.46 & 1.09 & 0.22 & 0.06 \\
\hline Salad dressing & 0.64 & 1.24 & 0.41 & $1 \cdot 16$ & 0.48 & 0.57 & 0.33 & 0.48 & 0.60 \\
\hline Animal fats and other fats & 0.33 & 0.29 & 0.04 & 0.19 & 1.14 & 0.40 & 0.32 & 0.21 & 0.11 \\
\hline Dipping sauces (cream base) & 0.02 & 0.00 & 0.01 & 0.03 & 0.04 & 0.06 & 0.01 & 0.01 & 0.01 \\
\hline Non-alcoholic beverages, homemade & $6 \cdot 13$ & 5.50 & 3.47 & 3.32 & 7.06 & 6.32 & 8.06 & 8.31 & 8.14 \\
\hline Natural juice & 2.93 & 0.21 & 1.95 & 0.30 & 3.45 & 3.07 & $5 \cdot 21$ & $4 \cdot 20$ & 5.85 \\
\hline Infusions (coffee, tea, herbal infusions) & 1.71 & 1.12 & 1.07 & 2.56 & 1.95 & 2.79 & 1.59 & 2.09 & 1.57 \\
\hline Milk with fruit or cereal & 0.70 & 0.33 & 0.46 & 0.05 & 0.73 & 0.40 & 1.15 & 1.67 & 0.73 \\
\hline Mate with sugar or artificially sweetened $\dagger$ & 0.57 & 3.84 & 0.00 & 0.02 & 0.00 & 0.00 & 0.00 & 0.00 & 0.00 \\
\hline Water with cocoa, with sugar or artificially sweetened & 0.17 & 0.00 & 0.00 & 0.03 & 0.80 & 0.00 & 0.12 & 0.33 & 0.00 \\
\hline Milk with tea or coffee & 0.06 & 0.00 & 0.00 & 0.35 & 0.13 & 0.07 & 0.00 & 0.02 & 0.00 \\
\hline Non-alcoholic beverages, ready-to-drink & 5.96 & 8.60 & $6 \cdot 60$ & $7 \cdot 70$ & 4.89 & 5.56 & 3.70 & 3.60 & 6.42 \\
\hline Soft drinks/soda, regular & 3.86 & 6.06 & 4.56 & $4 \cdot 20$ & 2.45 & $2 \cdot 81$ & $2 \cdot 87$ & $2 \cdot 81$ & 4.07 \\
\hline Juice and nectar (with sugar) & 1.26 & $2 \cdot 30$ & 1.51 & $2 \cdot 21$ & 0.97 & 1.32 & 0.34 & 0.51 & 0.79 \\
\hline Juice and nectar (unsweetened or artificially sweetened) & 0.60 & 0.13 & 0.46 & 1.21 & 1.32 & 0.50 & 0.22 & 0.05 & 1.09 \\
\hline Tea, ready-to-drink & 0.16 & 0.00 & 0.03 & 0.01 & 0.06 & 0.88 & 0.15 & 0.01 & 0.44 \\
\hline Other drinksf & 0.09 & 0.10 & 0.03 & 0.07 & 0.09 & 0.06 & 0.13 & 0.22 & 0.02 \\
\hline Processed meat & 4.64 & 5.39 & $5 \cdot 31$ & 5.85 & 5.58 & 5.52 & $2 \cdot 80$ & 1.51 & 4.94 \\
\hline Processed meat (e.g. sausage and cold cuts) & 2.46 & 2.73 & $2 \cdot 84$ & 3.94 & 2.88 & 2.96 & 1.77 & 0.88 & 1.88 \\
\hline Beef (processed) & 1.69 & $2 \cdot 41$ & 2.21 & 1.51 & 2.28 & 1.36 & 0.30 & 0.15 & 2.40 \\
\hline Fish (processed) & 0.32 & 0.12 & 0.13 & 0.32 & 0.25 & 0.80 & 0.48 & 0.29 & 0.51 \\
\hline Poultry (processed) & 0.17 & 0.13 & 0.13 & 0.07 & 0.18 & 0.39 & 0.25 & 0.19 & 0.15 \\
\hline Cookies, crackers and breakfast cereal & 3.99 & 5.94 & 4.55 & 3.56 & 3.41 & $5 \cdot 80$ & $2 \cdot 70$ & 2.62 & 2.89 \\
\hline Cookies & 1.28 & 2.86 & 1.33 & 1.56 & 0.77 & 1.73 & 0.37 & 0.83 & 0.60 \\
\hline Crackers & $1 \cdot 13$ & 2.09 & 1.91 & 0.37 & 0.71 & 0.94 & 0.47 & 0.89 & 0.61 \\
\hline Chips and other snacks & 1.01 & 0.59 & 1.02 & 0.73 & 1.06 & 2.00 & 1.47 & 0.71 & 0.94 \\
\hline Cereal, ready-to-eat or hot & 0.56 & 0.40 & 0.29 & 0.90 & 0.87 & $1 \cdot 12$ & 0.39 & 0.19 & 0.74 \\
\hline
\end{tabular}




\begin{tabular}{|c|c|c|c|c|c|c|c|c|c|}
\hline Food group/subgroup & ELANS & Argentina & Brazil & Chile & Colombia & Costa Rica & Ecuador & Peru & Venezuela \\
\hline Milk, yoghurt and soya drinks & 3.95 & 3.24 & 5.51 & 3.24 & $6 \cdot 17$ & $2 \cdot 84$ & 3.04 & 2.96 & $2 \cdot 65$ \\
\hline Milk, whole and whole milk products & 2.90 & 1.98 & 4.71 & 1.15 & 5.43 & 0.53 & 2.33 & 2.01 & $2 \cdot 27$ \\
\hline Milk, skimmed, $1 \%, 2 \%$ and products & 0.50 & 0.49 & 0.30 & 1.13 & 0.36 & 2.09 & 0.17 & $0 \cdot 14$ & 0.17 \\
\hline Yoghurt, regular, low-fat and/or low-sugar & 0.48 & 0.71 & 0.45 & 0.96 & 0.36 & 0.18 & 0.48 & 0.55 & 0.22 \\
\hline Soya drink and milk substitute & 0.06 & 0.05 & 0.06 & 0.00 & 0.02 & 0.04 & 0.05 & 0.25 & 0.00 \\
\hline Fruits & 3.70 & 2.07 & $2 \cdot 26$ & 4.45 & $5 \cdot 41$ & 3.40 & $5 \cdot 88$ & 4.66 & 2.94 \\
\hline Fruits & 2.07 & 1.99 & $2 \cdot 21$ & 2.65 & 1.81 & 1.91 & $2 \cdot 25$ & 2.96 & 0.80 \\
\hline Plantains (including pasteles) & 1.29 & 0.01 & 0.00 & 0.00 & $3 \cdot 31$ & $1 \cdot 14$ & 3.39 & $1 \cdot 17$ & 2.02 \\
\hline Avocado & 0.32 & 0.04 & 0.04 & 1.73 & 0.28 & 0.33 & 0.23 & 0.48 & 0.11 \\
\hline Fruits, sweetened & 0.02 & 0.03 & 0.00 & 0.07 & 0.01 & 0.02 & 0.01 & 0.05 & 0.01 \\
\hline Roots & 3.53 & 1.97 & $2 \cdot 12$ & $3 \cdot 16$ & 6.02 & $2 \cdot 37$ & 4.52 & 5.42 & 3.02 \\
\hline Potatoes, white & 2.54 & 1.88 & 1.37 & $3 \cdot 10$ & 4.05 & 1.57 & 3.64 & $4 \cdot 16$ & $1 \cdot 11$ \\
\hline Other root vegetables & 0.99 & 0.09 & 0.75 & 0.05 & 1.98 & 0.80 & 0.88 & 1.26 & 1.91 \\
\hline Sugars and sweets & 3.46 & 4.59 & 4.08 & $4 \cdot 11$ & $2 \cdot 71$ & 3.77 & 2.04 & $3 \cdot 19$ & $2 \cdot 65$ \\
\hline Candy (regular and low-calorie) & 1.22 & 1.69 & 1.62 & 1.84 & 0.99 & 1.56 & 0.35 & 0.90 & 0.64 \\
\hline Cakes, pies and pudding & 0.81 & 1.38 & 0.54 & 0.76 & 0.45 & 0.63 & 1.05 & 1.06 & 0.65 \\
\hline Sugar & 0.69 & 0.51 & 0.84 & 0.69 & 0.72 & 0.62 & 0.33 & 0.65 & 1.02 \\
\hline Ice cream, sherbet, frozen yoghurt & 0.62 & 0.97 & 0.81 & 0.76 & 0.46 & 0.87 & 0.21 & 0.39 & 0.32 \\
\hline Other candies (e.g. gelatin, peanut butter) & 0.12 & 0.05 & 0.27 & 0.07 & 0.09 & 0.08 & 0.11 & 0.18 & 0.02 \\
\hline Dairy products & 3.34 & 4.62 & 2.00 & 3.73 & 2.09 & $2 \cdot 68$ & 3.34 & $1 \cdot 17$ & 8.09 \\
\hline Cheese & 3.16 & 4.36 & 1.81 & 3.56 & 1.97 & 2.03 & 3.28 & 1.11 & 8.06 \\
\hline Cream & 0.18 & 0.26 & 0.19 & 0.16 & 0.12 & 0.65 & 0.06 & 0.06 & 0.03 \\
\hline Alcoholic beverages & 2.94 & 3.44 & $5 \cdot 13$ & 2.73 & 2.03 & $2 \cdot 16$ & 1.80 & 1.73 & 2.66 \\
\hline Alcohol beverages (low-alcohol grade) & 2.49 & 2.97 & 4.56 & 2.46 & 1.09 & 1.78 & 1.53 & 1.60 & $2 \cdot 33$ \\
\hline Alcohol beverages (high-alcohol grade) & 0.45 & 0.48 & 0.57 & 0.27 & 0.94 & 0.38 & 0.27 & 0.13 & 0.32 \\
\hline Beans, legumes and soyabeans & 2.46 & 0.23 & 3.97 & 1.38 & 2.56 & $6 \cdot 61$ & $2 \cdot 21$ & 1.54 & 1.69 \\
\hline Beans/legumes & 2.44 & 0.18 & 3.97 & 1.34 & 2.55 & $6 \cdot 61$ & $2 \cdot 21$ & 1.51 & 1.67 \\
\hline Soyabeans and soyabean products & 0.02 & 0.05 & 0.00 & 0.04 & 0.01 & 0.00 & 0.00 & 0.03 & 0.02 \\
\hline Vegetables & 1.75 & 1.18 & 1.03 & $2 \cdot 22$ & 1.68 & $2 \cdot 17$ & 3.03 & 2.02 & 1.77 \\
\hline Vegetables (non-dark green leafy) & 1.32 & 0.95 & 0.68 & 1.82 & 1.32 & 1.64 & 1.73 & 1.82 & 1.39 \\
\hline Tomatoes products & 0.16 & 0.09 & 0.16 & 0.08 & 0.22 & 0.17 & 0.34 & 0.01 & 0.20 \\
\hline Dark green leafy vegetables & 0.14 & 0.11 & 0.14 & 0.26 & 0.08 & 0.06 & 0.38 & 0.11 & 0.07 \\
\hline Spices and herbs & 0.13 & 0.03 & 0.05 & 0.06 & 0.06 & 0.29 & 0.59 & 0.09 & 0.11 \\
\hline Pizza & 1.06 & 4.83 & $1 \cdot 16$ & 1.25 & 0.04 & 0.00 & 0.02 & 0.02 & 0.01 \\
\hline Nuts and seeds & 0.30 & 0.21 & 0.20 & 0.19 & 0.60 & 0.48 & 0.55 & 0.22 & 0.04 \\
\hline Others§ & 0.98 & 0.17 & 0.32 & 0.31 & 1.14 & 0.84 & 1.27 & 3.35 & 0.59 \\
\hline
\end{tabular}

*Values presented are means and include the plausible reporters only ( $n$ 6648).

† Mate is an infusion prepared from leaves of yerba mate (llex paraguariensis) that is traditionally drunk in Latin America.

$\S$ Condiments, soups, supplements, dry mix chocolate, sandwiches, baby food and sweeteners. 
Latin American countries, based on a comprehensive and standardized dietary assessment, important differences in EI and food sources were observed between countries, genders and age groups. Overall, daily mean energy distribution from macronutrients was balanced (54, 30 and $16 \%$ of EI from carbohydrate, fat and protein, respectively). However, the relative distribution of energy from macronutrients differed between countries and these differences seemed to be culturally influenced by the types of foods habitually consumed in each country and region (by comparison between northern countries (Colombia, Venezuela, Ecuador, Peru and Costa Rica) $v$. southern countries (Argentina, Chile and Brazil)). When food sources of EI were analysed, a large contribution from refined carbohydrates, fat- and sugar-rich foods and beverages, and a limited contribution from complex carbohydrates and fruits and vegetables, were found in all ELANS countries.

As expected, in all ELANS countries, EI decreased progressively at older ages and was higher among men than women. The finding might be partially explained by the higher energy requirements associated with genderspecific growth and development during adolescence. Similar results were observed in national surveys conducted in Brazil ${ }^{(26)}$, the $\mathrm{USA}^{(6)}$ and Europe ${ }^{(27,28)}$. The mean daily total EI for plausible reporters in most of the ELANS countries was higher than previously described in national surveys in Latin America ${ }^{(29-36)}$, but lower than observed in the US adult population ${ }^{(37)}$. This difference could help explain the increased prevalence of overweight in the Latin American region, but also could be related to differences in the dietary assessment methodologies followed by other surveys.

Sociodemographic differences between populations living in the USA and Latin America can also help explain intake differences. Environmental exposures according to socio-economic status, such as living in a household with food insecurity, a situation frequently found in Latin America, can influence and determine the quantity and quality of food intake ${ }^{(38,39)}$.

There was a difference of more than $1674 \mathrm{~kJ} / \mathrm{d}(400 \mathrm{kcal} / \mathrm{d})$ between the country with the highest EI (Ecuador) and the country with the lowest EI (Chile). Notably, the lower EI in Chile was followed by the highest prevalence of excess weight $(68 \%)$ in the ELANS countries. Since these data represent only the plausible eaters, it should be highlighted that the obesity epidemic has multifactorial risk factors that are independently associated with weight gain such as dietary patterns (fat, sugar and refined grain intakes), physical activity, sedentary time and screen time, and sleep ${ }^{(40)}$.

Not only diet and rates of overweight and obesity show marked differences between countries, but also the whole umbrella of cardiometabolic risk factors. Recent studies revealed that $\mathrm{CHD}$ and stroke respectively cause 42.5 and $28.8 \%$ of the CVD mortality in Latin America ${ }^{(41)}$. A study of the behavioural and metabolic risk factors for CVD in three
South American countries (Argentina, Chile and Uruguay) indicated that $68.3 \%$ of individuals have three or more risk factors, including low intake of fruit and vegetables, low physical activity, hypertension, dyslipidaemia and diabetes, among others ${ }^{(42)}$. Prevalence of diabetes together with prevalence of obesity are the best indicators of diet-related diseases. Among South American countries, diabetes mellitus prevalence was $14.0 \%$ in Argentina ${ }^{(43)}, 10.8 \%$ in Costa Rica, 9\% in Chile, $7 \%$ in Brazil and $2 \cdot 8 \%$ in Ecuador ${ }^{(30,44-46)}$.

The proportions of energy derived from macronutrients were similar across age groups and genders in all countries. According to the Acceptable Macronutrient Distribution Ranges, which establish the range of intake for a specific energy source (protein, fat and carbohydrate) that is associated with reduced risk of chronic disease while providing intakes of essential nutrients ${ }^{(47)}$, ELANS countries reported a balanced and adequate distribution of macronutrients. However, a wide range of usual EI from carbohydrate was observed between countries, from 63\% in Peru to $51 \%$ in Argentina and Brazil. Different forms of compensation were observed among these countries. In Peru, higher EI derived from carbohydrate was compensated by a decrease in fat intake. Argentina compensated the lower energy derived from carbohydrate by a higher intake of fat, while Brazil compensated with a higher intake of protein. Both compensation by fat and compensation by protein (separately), in combination with a Western diet, might contribute to a positive energy balance and exacerbate the development of metabolic diseases $^{(48,49)}$. On the other hand, there is no consensus on whether the higher carbohydrate and lower fat intakes observed in Peru have an adverse effect on weight status or metabolic diseases. However, it is increasingly clear that both the amount and type of carbohydrate, protein and fat, and the interaction between them, are important variables in the development of obesity.

More than one-quarter of all EI in the ELANS countries came from the grains, pasta and bread group, regardless of gender and age group. Interestingly, in the southern countries bread (mainly wheat) was the main contributor to EI, while in the remaining countries rice was the main contributor. Different results were found in a previous study comparing Brazilian and North American food sources of energy in the adult population ${ }^{(50)}$. Although the consumption of bread was an important contributor to total EI in both countries (10.5 and $9.7 \%$ of EI in the USA and Brazil, respectively), protein mixed dishes was the main source of EI in the USA, while rice and dishes with rice and other ingredients were the main sources in Brazil. Unfortunately, wholegrain products are almost inexistent $(<2 \%$ of EI) as part of the cereals source within the Latin American diet. According to the US Dietary Guidelines ${ }^{(51)}$, a daily intake of whole grains of at least half of total grain consumption is recommended, which reinforces the low consumption of complex carbohydrates in Latin America. 
It is of concern that energy derived from food sources typically rich in fibre and micronutrients, such as whole grains, roots, fruits, vegetables, beans, fish and nuts, represented only $17.7 \%$ of EI. Although there is no single recommendation in terms of the percentage of energy expected from this group of foods, in recent years multiple diet-disease relationships have been established based on the insufficient consumption of these healthful food sources $^{(52)}$. In addition, more than $25 \%$ of total EI came from food groups that provide large quantities of sugar and fats, such as ready-to-eat foods, sugary drinks, pastries, chips and candies. Again, geographic distribution seems to have influenced the intake of non-alcoholic beverages, since in southern countries the main source of EI was industrialized/ready-to-drink beverages and in northern countries it was homemade beverages. These results are in accordance with the trends in dietary patterns of Latin American countries reported by Bermudez and Tucker $^{(1)}$ during an extensive review of consumption trends through household expenditure surveys available in FAO food country datasheets from 1990 and 1999. A reduced consumption of fruits and vegetables and increased fat and sugar intakes were found by the end of the 20th century. A more detailed description of total and added sugar intakes from ELANS is given elsewhere ${ }^{(53)}$.

The present study has several strengths. To our knowledge, it is the first and the largest representative study to examine Latin Americans living in urban areas in relation to EI and its food sources. Another strength of our study was the simultaneous application of two individual non-consecutive days of dietary recall across countries following a standardized methodology. This allowed us to carefully examine the dietary intake. Also, the estimates of usual energy and macronutrient intakes were based on statistical methods performed to appropriately adjust for intra-individual variability; such procedure allowed removal of extreme unlikely values ${ }^{(54)}$. Further, the careful data quality control methods (described elsewhere ${ }^{(55)}$ ) may have reduced the misreports of dietary intake, allowing more appropriate comparison of dietary data among countries.

The present study also has some limitations. The ELANS Study Group is aware that with the cross-sectional design of the project, causal and temporal inference is limited. Also, as ELANS data represent the dietary intake of the urban population of eight countries of Latin America, caution should be used in extrapolating these findings to other countries of South and Central America. Although dietary data from the rural population were absent, it should be highlighted that many more people are currently living in the urban setting (64 to $92 \%)^{(56)}$. Misreporting of EI, described as one of the main sources of error of the dietary assessment instruments based on selfreport ( $24 \mathrm{~h}$ recalls), if not controlled for in the current study, could have altered the mean EI. Under-reporting occurs in most adult populations, especially in women and in those persons with a higher BMI. As pointed out by other authors ${ }^{(57)}$, this could be attributable to participants' denial or poor ability to report dietary intake, or due to a tendency to provide socially desirable answers. Despite the limitations, these data are the best available to evaluate current dietary EI for the Latin American population.

\section{Conclusion}

In conclusion, daily mean EI was similar and the distribution of different macronutrients was balanced in eight Latin American countries participating in ELANS. The distribution of energy from macronutrients as well as the major food sources of EI differed between northern and southern countries. A large energy contribution from refined carbohydrates, high-fat and high-sugar foods and beverages, and limited intakes from complex carbohydrates, fruits and vegetables, was found in all ELANS countries. Findings from the present study can, at least partly, explain the role of dietary factors in the increased prevalence of overweight/obesity and other noncommunicable chronic diseases in Latin America. The dietary profile observed in the present study can support initiatives aimed at improving the diet quality and reducing the incidence of metabolic disorders and CVD in our region.

\section{Acknowledgements}

Acknowledgements: The authors would like to thank the staff and participants from each of the participating sites who made substantial contributions to ELANS. ELANSArgentina is thankful to ISALUD University for giving technical support to the fieldwork and to the Energy Balance Work Group from the International Life Sciences Institute (ILSI Argentina). Financial support: The ELANS is supported by a scientific grant from the Coca-Cola Company (Atlanta, GA, USA) and by grants and/or support from ILSI Argentina, Instituto Pensi/Hospital Infantil Sabara, Universidad de Costa Rica, Pontificia Universidad Católica de Chile, Pontificia Universidad Javeriana, Universidad Central de Venezuela/Fundación Bengoa, Universidad San Francisco de Quito and Instituto de Investigación Nutricional de Perú. The funders had no role in study design, data collection, analysis, the decision to publish or the preparation of this manuscript. Conflict of interest: M.F. is a member of the Board of Directors of Danone Institute International (Paris, France). The work of B.K. is financially supported in part by the Commission of the European Communities, Projects DYNAHEALTH (grant number H2020-633595) and LIFECYCLE (grant number H2020-SC1-2016-RTD), and the European Research Council Advanced Grant METAGROWTH (grant number ERC-2012-AdG 322605). The 
work of L.A.M. is supported in part by Centro de Investigación Biomédica en Red Fisiopatología de la Obesidad y Nutrición (CIBERObn) and Project Feel4Diabetes (grant number H2020-HCO-05-2014, contract 643708). I.K., G.G., A.R., L.Y.C.S., M.H.-C., M.C.Y.G., R.G.P., V.G., I.Z.Z. and A.N.P. declare that they have no potential conflicts of interest. Authorship: All authors were involved in the conception and design of the overall research plan. I.K. wrote the manuscript and had primary responsibility for the final content of the manuscript; I.Z.Z. assisted with the writing of the manuscript; A.N.P. conducted all statistical analyses; M.F., G.G., A.R., L.Y.C.S., M.H.-C., M.C.Y.G., R.G.P., V.G., B.K. and L.A.M. assisted with the interpretation of the results and provided critical review of the manuscript. Ethics of buman subject participation: The ELANS was conducted according to the guidelines laid down in the Declaration of Helsinki and all procedures involving human subjects were approved by the Western Institutional Review Board (\#20140605). The ELANS was also approved by a local ethics committee in each country. All participants gave their informed consent/assent before participation in the survey. The trial was registered at clinicaltrials.gov as NCT02226627.

\section{Supplementary material}

To view supplementary material for this article, please visit https://doi.org/10.1017/S1368980018001222

\section{References}

1. Bermudez OI \& Tucker KL (2003) Trends in dietary patterns of Latin American populations. Cad Saude Publica 19 , Suppl. 1, S87-S99.

2. Mikkila V, Vepsalainen H, Saloheimo T et al. (2015) An international comparison of dietary patterns in 9-11-yearold children. Int J Obes Suppl 5, Suppl. 2, S17-S21.

3. Popkin BM (2004) The nutrition transition: an overview of world patterns of change. Nutr Rev 62, 7 Pt 2, S140-S143.

4. Kelly T, Yang W, Chen CS et al. (2008) Global burden of obesity in 2005 and projections to 2030. Int J Obes (Lond) 32, 1431-1437.

5. Silventoinen K, Sans S, Tolonen H et al. (2004) Trends in obesity and energy supply in the WHO MONICA Project. Int J Obes Relat Metab Disord 28, 710-718.

6. Ladabaum U, Mannalithara A, Myer PA et al. (2014) Obesity, abdominal obesity, physical activity, and caloric intake in US adults: 1988 to 2010. Am J Med 127, 717-727.e12.

7. Popkin BM, Adair LS \& Ng SW (2012) Global nutrition transition and the pandemic of obesity in developing countries. Nutr Rev 70, 3-21.

8. Centers for Disease Control and Prevention (2004) Trends in intake of energy and macronutrients - United States, 19712000. MMWR Morb Mortal Wkly Rep 53, 80-82.

9. Austin GL, Ogden LG \& Hill JO (2011) Trends in carbohydrate, fat, and protein intakes and association with energy intake in normal-weight, overweight, and obese individuals: 1971-2006. Am J Clin Nutr 93, 836-843.

10. Fisberg M, Kovalskys I, Gomez G et al. (2016) Latin American Study of Nutrition and Health (ELANS): rationale and study design. BMC Public Health 16, 93.
11. Moshfegh AJ, Rhodes DG, Baer DJ et al. (2008) The US Department of Agriculture automated multiple-pass method reduces bias in the collection of energy intakes. Am J Clin Nutr 88, 324-332.

12. Kovalskys I, Fisberg M, Gomez G et al. (2015) Standardization of the food composition database used in the Latin American Nutrition and Health Study (ELANS). Nutrients 7, 7914-7924.

13. Block G, Dresser CM, Hartman AM et al. (1985) Nutrient sources in the American diet: quantitative data from the NHANES II survey. II. Macronutrients and fats. Am J Epidemiol 122, $27-40$.

14. Harttig U, Haubrock J, Knuppel S et al. (2011) The MSM program: web-based statistics package for estimating usual dietary intake using the Multiple Source Method. Eur J Clin Nutr 65, Suppl. 1, S87-S91.

15. Sartorelli DS, Barbieri P \& Perdona GC (2014) Fried food intake estimated by the multiple source method is associated with gestational weight gain. Nutr Res 34, 667-673.

16. Selem SS, Castro MA, Cesar CL et al. (2014) Associations between dietary patterns and self-reported hypertension among Brazilian adults: a cross-sectional populationbased study. J Acad Nutr Diet 114, 1216-1222.

17. Sangalli CN, Rauber F \& Vitolo MR (2016) Low prevalence of inadequate micronutrient intake in young children in the south of Brazil: a new perspective. Br J Nutr 116, 890-896.

18. de Onis M, Onyango AW, Borghi E et al. (2007) Development of a WHO growth reference for school-aged children and adolescents. Bull World Health Organ 85, 660-667.

19. Fisberg RM \& Marchioni DML (2012) Manual de Avaliação de Consumo Alimentar em Estudos Populacionais: A Experiência do Inquérito de Saúde em São Paulo (ISA). São Paulo: Faculdade de Saúde Pública, Universidade de São Paulo; available at http://www.gac-usp.com.br/manual-einstrumentos-avaliação-dietética.php

20. Gerrior S, Juan W \& Basiotis P (2006) An easy approach to calculating estimated energy requirements. Prev Chronic Dis 3, A129.

21. McCrory MA, Hajduk CL \& Roberts SB (2002) Procedures for screening out inaccurate reports of dietary energy intake. Public Health Nutr 5, 873-882.

22. Black AE \& Cole TJ (2000) Within- and between-subject variation in energy expenditure measured by the doubly-labelled water technique: implications for validating reported dietary energy intake. Eur J Clin Nutr 54, 386-394.

23. Vinken AG, Bathalon GP, Sawaya AL et al. (1999) Equations for predicting the energy requirements of healthy adults aged 18-81 y. Am J Clin Nutr 69, 920-926.

24. Mendez MA, Popkin BM, Buckland G et al. (2011) Alternative methods of accounting for underreporting and overreporting when measuring dietary intake-obesity relations. Am J Epidemiol 173, 448-458.

25. Black AE (2000) Critical evaluation of energy intake using the Goldberg cut-off for energy intake:basal metabolic rate. A practical guide to its calculation, use and limitations. Int J Obes Relat Metab Disord 24, 1119-1130.

26. Souza RA, Yokoo EM, Sichieri R et al. (2015) Energy and macronutrient intakes in Brazil: results of the first nationwide individual dietary survey. Public Health Nutr 18, 3086-3095.

27. Temme E, Huybrechts I, Vandevijvere S et al. (2010) Energy and macronutrient intakes in Belgium: results from the first National Food Consumption Survey. Br J Nutr 103, 1823-1829. 
28. Ruiz E, Avila JM, Valero T et al. (2015) Energy intake, profile, and dietary sources in the Spanish population: findings of the ANIBES Study. Nutrients 7, 4739-4762.

29. Romero-Martínez M, Shamah-Levy T, Franco-Núñez A et al.(2013) Encuesta Nacional de Salud y Nutrición 2012: diseño y cobertura. Salud Publica Mex 55, Suppl. 2, S332-S340.

30. Freire W, Ramírez-Luzuriaga M, Belmont P et al. (2014) Tomo I: Encuesta Nacional de Salud y Nutrición de la Población Ecuatoriana de cero a 59 años, ENSANUT-ECU 2012. Quito: Ministerio de Salud Pública/Instituto Nacional de Estadísticas y Censos; available at http://www.ecuador encifras.gob.ec/documentos/web-inec/Estadisticas_Sociales/ ENSANUT/MSP_ENSANUT-ECU_06-10-2014.pdf

31. Fonseca Z, Heredia A, Ocampo R et al. (2011) Encuesta Nacional de la Situación Nutricional en Colombia 2010 - ENSIN. Bogotá: Instituto Colombiano de Bienestar Familiar.

32. Ministerio de Salud de Argentina (2012) Alimentos Consumidos en Argentina. Resultados de la Encuesta Nacional de Nutrición y Salud - ENNyS 2004/5. Buenos Aires: Ministerio de Salud.

33. Ministerio de Salud de Chile (2014) Encuesta Nacional de Consumo Alimentario. Santiago: Ministerio de Salud.

34. Ministerio de Salud de Peru (2006) Encuesta Nacional de Indicadores Nutricionales, Bioquímicos, Socioeconómicos y Culturales Relacionados con las Enfermedades Crónicas Degenerativas. Lima: Ministerio de Salud.

35. Instituto Brasileiro de Geografia e Estatística (2010) Pesquisa de Orçamentos Familiares: 2008-2009. Rio de Janeiro: IBGE.

36. Instituto Nacional de Estadística de Venezuela (2014) Encuesta de Seguimiento al Consumo de Alimentos (ESCA). Caracas: Instituto Nacional de Estadística.

37. Ford ES \& Dietz WH (2013) Trends in energy intake among adults in the United States: findings from NHANES. $A m J$ Clin Nutr 97, 848-853.

38. Andrieu E, Darmon N \& Drewnowski A (2006) Low-cost diets: more energy, fewer nutrients. Eur J Clin Nutr 60, 434-436.

39. Coleman-Jensen A, Rabbitt MP, Gregory CA et al. (2016) Housebold Food Security in the United States in 2015. Economic Research Report no. ERR-215. Washington, DC: US Department of Agriculture, Economic Research Service.

40. Hruby A \& Hu FB (2015) The epidemiology of obesity: a big picture. Pharmacoeconomics 33, 673-689.

41. Fernando L, Pamela S \& Alejandra L (2014) Cardiovascular disease in Latin America: the growing epidemic. Prog Cardiovasc Dis 57, 262-267.

42. Rubinstein AL, Irazola VE, Calandrelli M et al. (2015) Multiple cardiometabolic risk factors in the Southern Cone of Latin America: a population-based study in Argentina, Chile, and Uruguay. Int J Cardiol 183, 82-88.

43. Shen J, Kondal D, Rubinstein A et al. (2016) A multiethnic study of pre-diabetes and diabetes in LMIC. Glob Heart 11, 61-70.

44. Ministerio de Salud, Dirección de Vigilancia de la Salud (2014) Análisis de Situación de Salud Costa Rica. San José: Ministerio de Salud; available at http://www.ministerio desalud.go.cr/index.php/vigilancia-de-la-salud/analisis-desituacion-de-salud/2618-analisis-de-situacion-de-salud-en-costarica/file.

45. Ministerio de Salud, Gobierno de Chile (2011) Encuesta Nacional de Salud ENS Chile 2009-2010: Tomo I. Santiago: MINSAL.

46. Ministério do Planejamento, Orçamento e Gestão, Instituto Brasileiro de Geografia e Estatística \& Diretoria de Pesquisas, Coordenação de Trabalho e Rendimento (2014) Pesquisa Nacional de Saúde 2013. Percepção do Estado de Saúde, Estilos de Vida e Doenças Crônicas. Brasil, Grandes
Regiões e Unidades da Federação. Rio de Janeiro: IBGE; available at ftp://ftp.ibge.gov.br/PNS/2013/pns2013.pdf

47. Institute of Medicine (2005) Dietary Reference Intakes for Energy, Carbohydrate, Fiber, Fat, Fatty Acids, Cholesterol, Protein, and Amino Acids. Washington, DC: National Academies Press.

48. Pesta DH \& Samuel VT (2014) A high-protein diet for reducing body fat: mechanisms and possible caveats. Nutr Metab (Lond) 11, 53.

49. Numao S, Kawano H, Endo N et al. (2012) Short-term lowcarbohydrate/high-fat diet intake increases postprandial plasma glucose and glucagon-like peptide- 1 levels during an oral glucose tolerance test in healthy men. Eur J Clin Nutr 66, 926-931.

50. Bezerra IN, Goldman J, Rhodes DG et al. (2014) Difference in adult food group intake by sex and age groups comparing Brazil and United States nationwide surveys. Nutr J 13, 74 .

51. US Department of Health and Human Services \& US Department of Agriculture (2015) 2015-2020 Dietary Guidelines for Americans, 8th ed. http://www.health.gov/ dietaryguidelines/2015/guidelines/ (accessed June 2017).

52. Micha R, Khatibzadeh S, Shi P et al. (2015) Global, regional and national consumption of major food groups in 1990 and 2010: a systematic analysis including 266 countryspecific nutrition surveys worldwide. BMJ Open $\mathbf{5}$, e008705.

53. Fisberg M, Kovalskys I, Gomez G et al. (2018) Total and added sugar intake: assessment in eight Latin American countries. Nutrients 10, E389.

54. Murphy SP \& Barr SI (2011) Practice paper of the American Dietetic Association: using the Dietary Reference Intakes. J Am Diet Assoc 111, 762-770.

55. Fisberg M, Kovalskys I, Gómez Salas G et al. (2017) Developing a cooperative multicenter study in Latin America: lessons learned from the Latin American Study of Nutrition and Health Project. Rev Panam Salud Publica 41, e111.

56. World Bank (2015) Urban population (\% of total). World Development Indicators. http://data.worldbank.org/indicator/ SP.URB.TOTL.IN.ZS/countries (accessed January 2016).

57. Hebert JR, Peterson KE, Hurley TG et al. (2001) The effect of social desirability trait on self-reported dietary measures among multi-ethnic female health center employees. Ann Epidemiol 11, 417-427.

\section{Appendix}

\section{Members of the ELANS Study Group}

Chairs: Mauro Fisberg and Irina Kovalskys.

Co-Chair: Georgina Gómez Salas.

Core Group Members: Mauro Fisberg, Irina Kovalskys, Attilio Rigotti, Lilia Yadira Cortés Sanabria, Georgina Gómez Salas, Martha Cecilia Yépez García, Rossina Gabriella Pareja and Marianella Herrera-Cuenca.

External Advisory Board: Berthold Koletzko, Luis A. Moreno, Michael Pratt and Katherine L. Tucker.

Project Managers: Viviana Guajardo and Ioná Zalcman Zimberg.

International Life Sciences Institute (ILSI) - Argentina: Irina Kovalskys, Viviana Guajardo, Maria Paz Amigo, Ximena Janezic, Andrea Lorena Favieri, Myriam Etcheverry and Fernando Cardini. 
Instituto Pensi, Hospital Infantil Sabara - Brazil: Mauro Fisberg, Ioná Zalcman Zimberg and Natasha Aparecida Grande de França.

Pontificia Universidad Catolica de Chile: Attilio Rigotti, Guadalupe Echeverría, Leslie Landaeta and Óscar Castillo. Pontificia Universidad Javeriana - Colombia: Lilia Yadira Cortés Sanabria, Luz Nayibe Vargas, Luisa Fernanda Tobar and Yuri Milena Castillo.

Universidad de Costa Rica: Georgina Gómez, Rafael Monge Rojas and Anne Chinnock.

Universidad San Francisco de Quito - Ecuador: Martha Cecilia Yépez García, María Elisa Herrera Fontana, Mónica Villar Cáceres and María Belén Ocampo.
Instituto de Investigación Nutricional - Peru: Rossina Pareja Torres, Maria Reyna Liria, Krysty Meza, Mellisa Abad and Mary Penny.

Universidad Central de Venezuela: Marianella HerreraCuenca, Maritza Landaeta, Betty Méndez, Maura Vasquez, Guillermo Ramirez and Pablo Hernández.

Statistical analysis: Alexandre DP Chiavegatto Filho and Bruno Zoca.

Accelerometry analysis: Priscila Bezerra Gonçalves and Claudia Alberico.

Physical activity advisor: Gerson Luis de Moraes Ferrari.

Dietary intake advisor: Ágatha Nogueira Previdelli. 